\title{
Epithelial respiratory cells from cystic fibrosis patients do not possess specific Pseudomonas aeruginosa-adhesive properties
}

\author{
M. C. PLOTKOWSKI*†, M. CHEVILLARD*, D. PIERROT*, D. ALTEMAYER* and E. PUCHELLE* \\ *INSERM U314, 45, rue Cognacq Jay, 51092 Reims Cedex, France and †Department of Microbiology and \\ Immunology, UERJ, 20550 Rio de Janeiro, Brazil
}

\begin{abstract}
Summary. Nasal polyp cells in primary culture from cystic fibrosis (CF) and non-CF patients were compared for the ability to bind Pseudomonas aeruginosa cells and for the presence of sulphated glycoconjugates at the epithelial cell surface. Quantitation of bacterial adhesion, by scanning electronmicroscopy, showed no significant difference between the cells cultured from CF and non-CF patients. Micro-organisms associated with ciliated cells were mainly aggregated, in contrast with those from non-ciliated cells. Sulphated glycoconjugates were identified on cells cultured from both $\mathrm{CF}$ and non-CF patients, regardless of whether or not these cells had attached bacteria. A matrix-like material that surrounded the aggregated bacteria was more prominent on cells cultured from CF patients than on those from non-CF patients. The interaction of aggregated $P$. aeruginosa cells with polyp cells cultured from both CF and non-CF patients appeared to occur by means of this matrix material. Our findings suggest that chronic colonisation of the airways of CF patients cannot be explained by an increased affinity between the $P$. aeruginosa cells and the respiratory cell surface receptors in the $C F$ patient. Nevertheless, the in-vitro observation that the matrix surrounding the bacteria reacted with a monoclonal antibody against respiratory mucins allows us to speculate that increased mucin secretion by cells from CF patients might, in vivo, play a decisive role in the interaction between $P$. aeruginosa and the respiratory epithelium.
\end{abstract}

\section{Introduction}

Chronic colonisation and infection of the respiratory tract with Pseudomonas aeruginosa occurs commonly in patients with cystic fibrosis (CF). Several factors may contribute to the susceptibility of these patients to infection by the organism. In normal individuals, entrapping of inhaled micro-organisms by respiratory mucus and subsequent elimination by ciliary beating protects the respiratory tract against infection. However, when the ciliary clearance is decreased, bacteria may multiply and infect the epithelial cells. In CF, severe reduction of the mucociliary transport has been described. ${ }^{1}$ Moreover, $P$. aeruginos $a$ cells adhere avidly to human respiratory mucins. ${ }^{2,3}$ This property, as well as the presence of chemotactic factors in the mucins from CF patients, ${ }^{4}$ may play a decisive role in the infection of these patients. This hypothesis was supported by immunohistopathological studies on the airways of CF patients, which showed that the $P$. aeruginosa cells remained sequestered within an exudate, rather than attached to undamaged epithelium. ${ }^{5}$

Received 11 Dec. 1990; accepted 24 April 1991.
To explain the specificity of $P$. aeruginosa as a respiratory pathogen in CF patients, the presence of some component of respiratory mucins unique to $\mathrm{CF}$ patients must be assumed. However, recent in-vitro studies showed that most mucin-like glycopeptides from the sputum of CF patients allowed less adhesion of $P$. aeruginosa cells than did glycopeptides from the respiratory secretions of bronchitic patients. ${ }^{6}$

The specific interaction between cell surface glycoconjugate receptors and microbial adhesins is an important step in the pathogenesis of infectious diseases. Although the adhesion of $P$. aeruginosa to normal respiratory cells from different animal species, including man, has been studied exhaustively, ${ }^{2,7-12}$ the adhesion to respiratory cells from CF patients has not been investigated, to our knowledge.

Epithelial cells from CF patients differ from those of non-CF patients in permeability to chloride ions $^{13,14}$ and in releasing high-mol.-wt glycoconjugates which are more highly sulphated than are those from the cells of non-CF patients. ${ }^{15}$ This high sulphate content of the cell-surface glycoconjugates may affect the interaction of the bacteria with the airways. ${ }^{15,16}$ Alternatively, CF results in defective glycosylation of the transmembrane conductance regulator protein (CFTR), ${ }^{17}$ and defective glycosylation of cell surface 
glyconjugates may also occur, imparting specific adhesive properties for $\boldsymbol{P}$. aeruginosa epithelial respiratory cells.

The present study evaluated whether the adhesion of $P$. aeruginosa cells to cultured respiratory epithelial cells from CF patients differed from that to cells from non-CF patients. Because increased sulphation of cellsurface glycoconjugates might augment the adhesion of $P$. aeruginosa to CF cells, we also investigated the occurrence of sulphated carbohydrates on the surface of respiratory epithelial cells cultured from CF and non-CF patients.

\section{Materials and methods}

\section{Cell culture}

Epithelial respiratory cells were cultured from 13 small explants, each c. $1 \mathrm{~mm}^{2}$ in size, which were dissected from nasal polyps from five CF patients and from four non-CF patients, who were undergoing polypectomy for nasal obstruction. The explants were cultured on type I collagen matrix in hormonesupplemented serum-free defined RPMI 1640 medium (Sigma), as described elsewhere. ${ }^{18}$

\section{Bacteria}

A non-mucoid strain of $P$. aeruginosa isolated from the expectorated sputum of a CF patient was maintained in Trypticase Soy Broth (TSB; Institut Pasteur) containing glycerol $20 \% \mathrm{v} / \mathrm{v}$ at $-20^{\circ} \mathrm{C}$. For adhesion assays, bacteria were cultured overnight in TSB at $28^{\circ} \mathrm{C}$, harvested by centrifugation and resuspended in RPMI 1640 medium containing $20 \mathrm{mM} \mathrm{N}-2$ hydroxyethylpiperazine-N'2 ethanesulphonic acid (RPMIHEPES). The optical density of this suspension was adjusted to 0.5 at a wavelength of $640 \mathrm{~nm}$ (Beckman M9 Spectrophotometer). This optical density corresponded to $c$. $(5-8) \times 10^{8} \mathrm{cfu} / \mathrm{ml}$. Immediately before the adhesion assays, the bacteria were dispersed with a syringe fitted with a 25 gauge needle.

\section{Adhesion assays}

After incubation for 4-6 days (as above), the supplemented RPMI medium in the culture wells was removed and replaced by $200 \mu$ l of the $P$. aeruginosa suspension. The cultures were incubated for $1 \mathrm{~h}$ at $37^{\circ} \mathrm{C}$, then rinsed four times with gentle manual agitation with $0.5 \mathrm{ml}$ of $0.1 \mathrm{M}$ phosphate-buffered saline, $\mathrm{pH} 7.2$ (PBS), and fixed with glutaraldehyde $2.5 \%$ in PBS for $2 \mathrm{~h}$ at $4^{\circ} \mathrm{C}$, unless otherwise stated.

Quantitation of bacterial adhesion. Fixed epithelial cells were rinsed with PBS, dehydrated through a graded series of washes with ethanol, dried to the critical point, then coated with gold-palladium and examined with a scanning electronmicroscope (SEM) (Philips Model 525). Because the contours of nonciliate cells were not always discernible, we could not directly determine the number of adherent bacteria per epithelial cell. Therefore, to quantitate adhesion of $P$. aeruginosa cells, we used an image analyser (Biocom 500) connected to the SEM to draw the outlines of ciliate cells and, for each microscope field, to determine the surface areas, in $\mu \mathrm{m}^{2}$, of both ciliate (CC) and non-ciliate cells (NCC). In each culture examined, adherent bacteria were counted in at least 150 microscope fields at a magnification of $\times 2700$. The working distance $(10 \mathrm{~mm})$, angle $\left(20^{\circ}\right)$ and voltage $(15 \mathrm{kV})$ remained constant throughout the study.

Preliminary assays showed that the $P$. aeruginosa cells adhering to $\mathrm{CC}$ or NCC cultured from CF or non-CF patients were often present as clumps. The numbers of bacteria in these clumps could not be determined. So, each clump was counted as one bacterium and the distribution of clumps was assessed. This approach underestimated the total adhesion of $P$. aeruginosa cells.

\section{Localisation of sulphated carbohydrates on the surfaces of epithelial cells}

Glutaraldehyde-fixed epithelial respiratory cells cultured from three CF and three non-CF nasal polyps were rinsed in PBS and exposed, for $24 \mathrm{~h}$ at room temperature, to the High Iron Diamine (HID) solution, prepared as described by Spicer et al. ${ }^{19}$ Subsequently, the specimens were rinsed in PBS, dehydrated through graded ethanol washes, embedded in an epoxy resin and observed, without uranyl or lead acetate staining, in a transmission electronmicroscope (TEM, Jeol 200 CX). Control cultures were exposed for $24 \mathrm{~h}$ to a solution of HID from which $\mathrm{FeCl}_{3}$ was omitted.

\section{Evaluation of the role of mucins in bacterial aggregation}

The role of the mucins secreted by respiratory cells in causing the aggregation of $P$. aeruginosa cells was evaluated by fluorescence microscopy and electronmicroscopy. Epithelial respiratory cells with adherent bacteria were fixed with paraformaldehyde $4 \%$ in PBS for $2 \mathrm{~h}$ at $4^{\circ} \mathrm{C}$, rinsed with PBS, and exposed for $1 \mathrm{~h}$ to the monoclonal antibody (MAb) 17B1 against the respiratory mucin of rhesus monkeys ${ }^{20}$ (kindly provided by Dr R. Wu, University of California, Davis, CA, USA). The antibody was used at a concentration of $10 \mathrm{mg} / \mathrm{L}$ in PBS containing bovine serum albumin $1 \%$ (PBS-BSA). Subsequently, the cultures were rinsed in PBS and exposed to an anti-mouse IgG-biotin complex (Amersham International, Bucks) diluted in PBS-BSA. For fluorescence microscopy, the cells were exposed to a 1 in 25 streptavidin-FITC complex at a 1 in 25 dilution. To favour the visualisation of aggregated bacteria, cultures were then exposed to a rabbit antibody against the somatic $P$. aeruginosa antigen (Institut Pasteur) at a 1 in 10 dilution and, finally, to an anti-rabbit IgG-Texas Red complex (Amersham). The cultures were then observed with a light micro- 

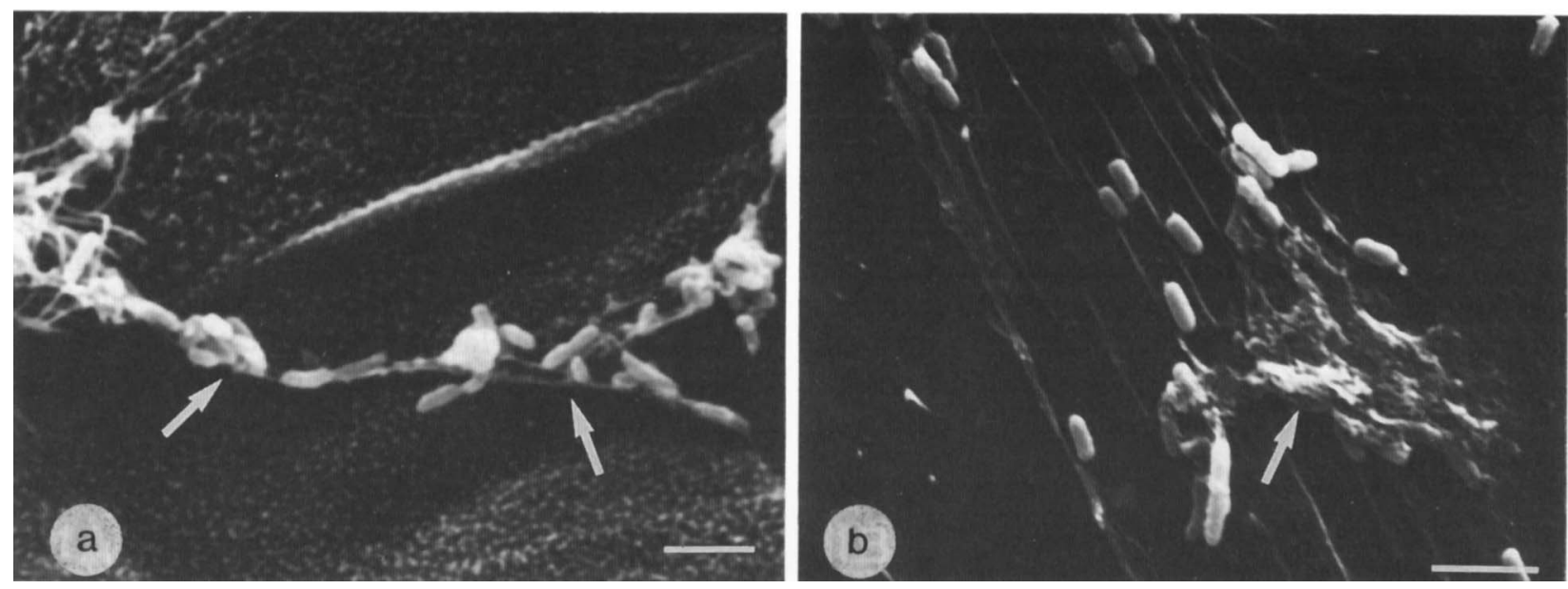

Fig. 1. Scanning electronmicrographs of respiratory epithelial cells from a CF patient in culture showing: a, the presence of strands of secretion with adherent bacteria (arrows) and, b, an amorphous material (arrow) associated with the bacteria. Bars $=4 \mu \mathrm{m}$.

scope equipped with epifluorescent illumination (Axiophot, Zeiss). For electronmicroscopy, the cells were treated, as above, as far as exposure to the anti-mouse IgG-biotin complex. Subsequently, they were treated with a streptavidin-colloidal gold $(5 \mathrm{~nm})$ complex (Bio Cell), fixed with osmium tetroxide $1 \%$ in $0 \cdot 1 \mathrm{M}$ cacodylate buffer, $\mathrm{pH} 7 \cdot 4$, containing ruthenium red $0.05 \% \mathrm{w} / \mathrm{v}$, dehydrated with graded ethanols prepared with cacodylate-ruthenium red buffer and embedded in epoxy resin. Ultrathin $(90 \mathrm{~nm})$ and thick $(1.0 \mu \mathrm{m})$ sections were examined in the TEM operating at 80 or $200 \mathrm{kV}$.

\section{Statistical analyses}

The Wilcoxon matched-pairs test was used to compare the mean numbers of adherent bacteria $/ \mu \mathrm{m}^{2}$ on $\mathrm{CC}$ and $\mathrm{NCC}$, and the percentage of aggregated bacteria adherent to $\mathrm{CC}$ and $\mathrm{NCC}$ in each culture examined. The comparisons between the cultures from $\mathrm{CF}$ and non-CF patients for the mean number of adherent $P$. aeruginosa cells, the percentage of CC with aggregated micro-organisms, and the percentage of aggregated bacteria adherent to $\mathrm{CC}$ and $\mathrm{NCC}$ were done by the Mann-Whitney test.

\section{Results}

\section{Characteristics of the epithelial cell cultures}

Explants dissected from nasal polyps from $\mathrm{CF}$ and non-CF patients yielded cellular outgrowth in which rapid ciliary activity was evident by optical microscopy. Both CC and NCC were observed, by SEM, in the cellular outgrowth but the $\mathrm{CC}$ were more frequent near the excised polyp. At the periphery of the cultures, migrating cells, with pseudopodial projections extending towards the collagen matrix and unfolded apical cell membranes, were identified (not shown). These migrating cells have a specific adhesive property for $P$. aeruginosa ${ }^{21}$ and were excluded from the quantitative study.

In five of the 13 cultures from CF patients, we observed strands of secretion that linked one $\mathrm{CC}$ to another. Adherent bacteria were identified in these strands (fig. 1a). In the other cultures from CF patients, or in those from non-CF patients, these strands of secretion were rarely observed. Moreover, in most of the cultures from $\mathrm{CF}$ patients we detected an amorphous material lying over the epithelial cells. The bacteria were closely associated with this material (fig. 1b).

\section{Adhesion of $P$. aeruginosa to epithelial respiratory cells}

$P$. aeruginosa cells were seen, by SEM, to adhere to both $\mathrm{CC}$ and NCC cultured from CF and non-CF patients, but a marked difference was noted between the patterns of adhesion to these two cell types. Bacteria associated with $\mathrm{CC}$ were mainly present as aggregates (fig. 2), whereas bacteria associated with NCC usually were not aggregated. This difference was

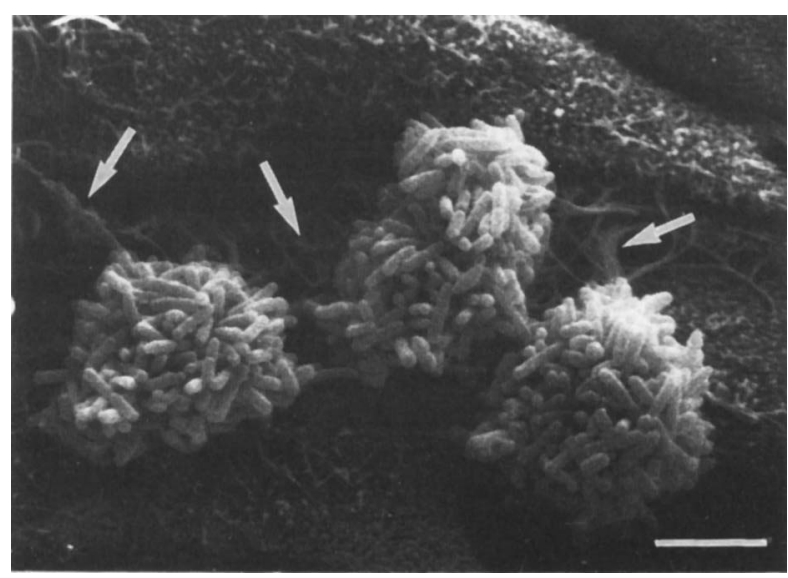

Fig. 2. Scanning electronmicrograph of respiratory epithelial cells from a CF patient, showing aggregated $P$. aeruginosa cells associated with the cilia (arrows). Bar $=6 \mu \mathrm{m}$. 


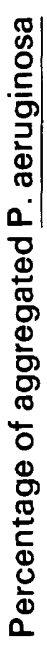

瞏

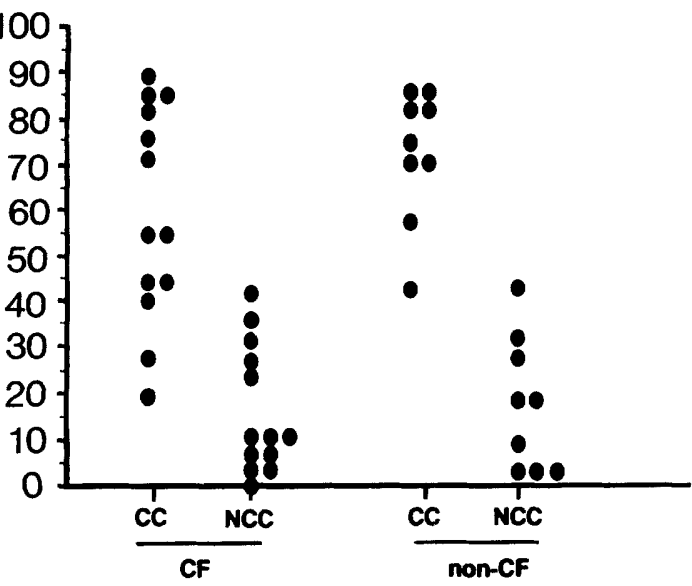

Fig. 3. Percentages of aggregated $P$. aeruginosa cells associated with ciliate (CC) and non-ciliate cells (NCC) in cell cultures from $\mathrm{CF}$ and non-CF patients. The Wilcoxon matched-pairs test showed a significant difference between the percentage of bacteria associated with the CC and NCC $(p<0 \cdot 01)$.

statistically significant for cultures from both $\mathrm{CF}$ and non-CF patients $(\mathrm{p}<0 \cdot 001$, fig. 3 ). No difference was noted between cultures from $\mathrm{CF}$ and non-CF patients with respect to the percentages of aggregated $P$. aeruginosa cells associated with CC or NCC (fig. 3 ).

The adhesion of $P$. aeruginosa cells to CC surfaces was significantly higher than to NCC surfaces, regardless of whether the cells were from $\mathrm{CF}$ or non$\mathrm{CF}$ patients $(\mathrm{p}<0.01$, fig. 4$)$. However, no significant difference was observed between cell cultures from $\mathrm{CF}$ and non-CF patients with regard to either the number of bacteria adhering to CC or NCC surfaces (fig. 4), or to the percentage of $\mathrm{CC}$ with attached bacteria (fig. 5).

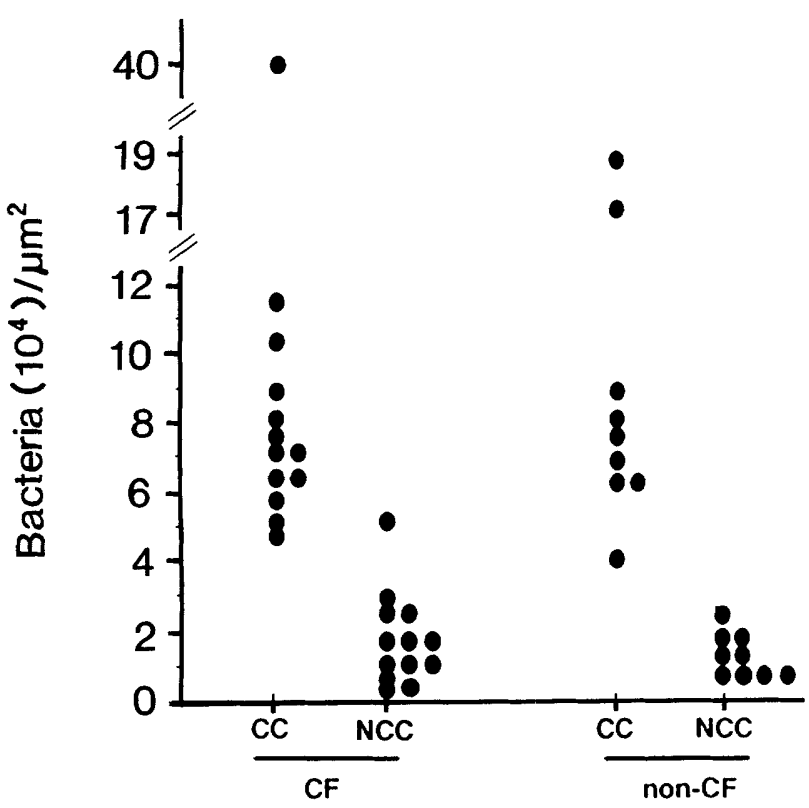

Fig. 4. Adhesion of $P$. aeruginosa cells to ciliate (CC) and non-ciliate (NCC) respiratory cells in culture from $\mathrm{CF}$ and non-CF patients.

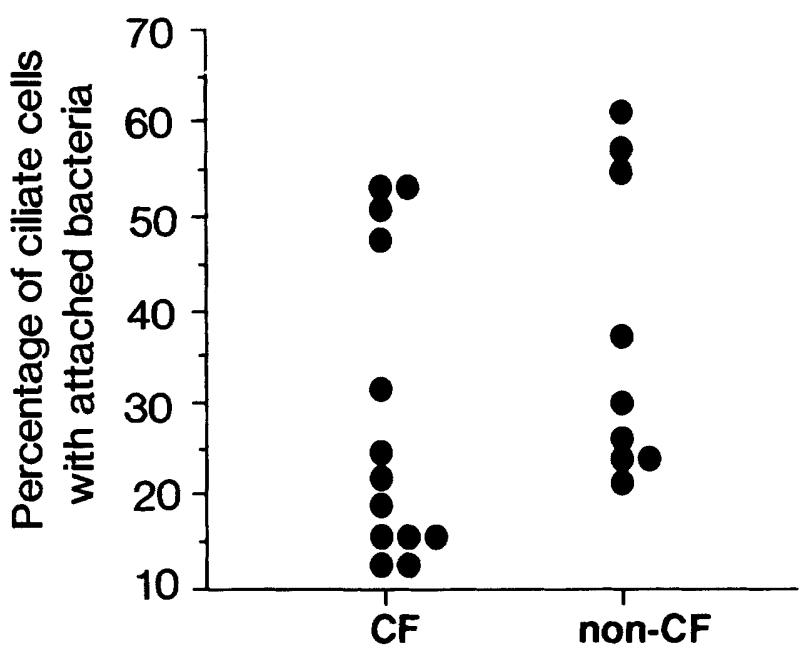

Fig. 5. Percentages of ciliate cells from CF and non-CF patients showing attached $P$. aeruginosa cells.

\section{Transmission electronmicroscopy}

During observation by TEM of the cells cultured from $C F$ and non-CF patients, $P$. aeruginosa cells were never seen to be interspersed between the cilia but were observed at the extremities of the cilia, usually as aggregates of bacteria surrounded by a matrix-like material. Examination of thick sections of cells from CF patients showed a continuity between the cilia and this matrix-like material (fig. 6). The interaction of aggregated bacteria with NCC also appeared to occur by means of this surrounding matrix (fig. $7 \mathrm{c}$ ).

\section{HID staining of $C F$ and non- $C F$ epithelial respiratory cells}

Sulphated glycoconjugates were identified by the HID method on respiratory cells from CF and nonCF patients regardless of whether these cells had attached bacteria or not, as shown in fig. 7. No general difference was noticed between the electron density of the surfaces of apical cells cultured from CF and non-

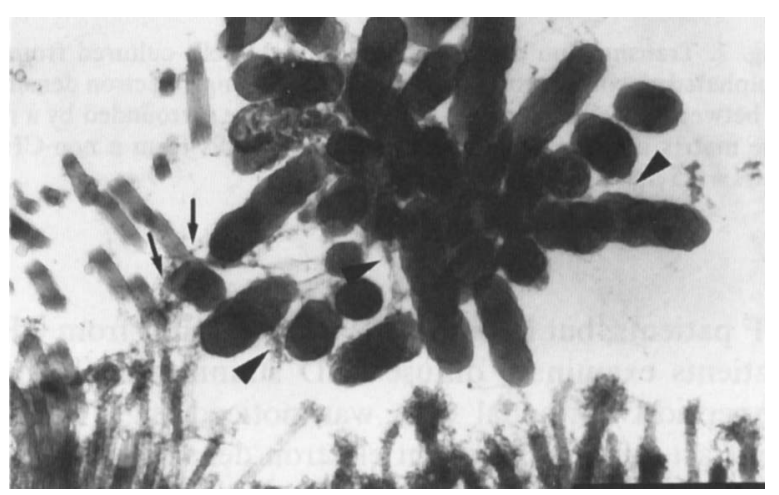

Fig. 6. Transmission electronmicrograph from a thick section of cells cultured from a CF patient. Aggregated $P$. aeruginosa cells are surrounded by a matrix-like material (arrowheads) which seemed to promote the interaction between the bacteria and the ciliate cells (arrows). $\mathrm{Bar}=2.5 \mu \mathrm{m}$ 


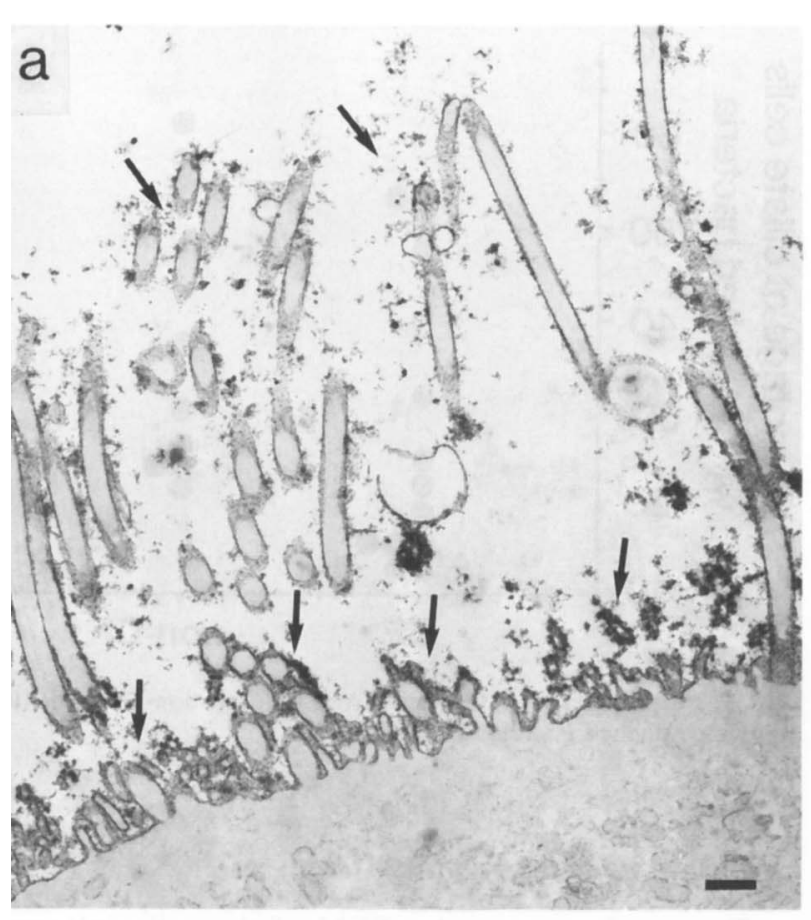

b
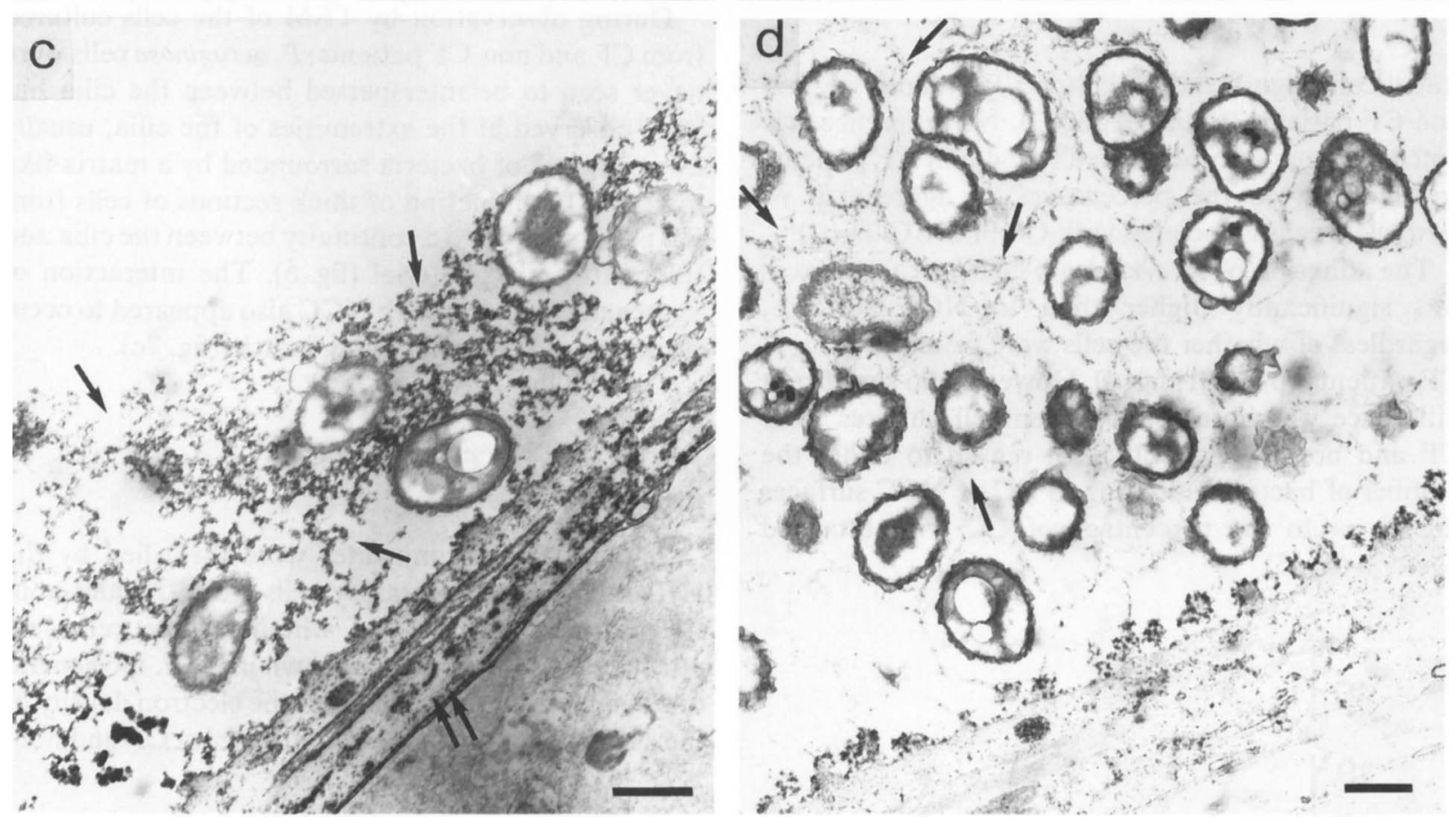

Fig. 7. Transmission electronmicrographs of cells cultured from $C F(a, c)$ and non-CF (b, d) patients labelled with the HID solution. Sulphated glycoconjugates are revealed by the high electron density at the epithelial surfaces (arrows): note a, HID-labelled matrix material is between the cilia (arrows); $\mathbf{c}$, the bacteria are surrounded by a matrix (arrows) which is more abundant and more heavily stained than is the matrix around bacteria associated with cells from a non-CF patient d, and the uppermost cell (double arrows) is diffusely stained. Bars $=0.5 \mu \mathrm{m}$.

$\mathrm{CF}$ patients, but in one of the three cultures from CF patients examined, diffuse HID staining of all the uppermost epithelial cells was noticed (fig. 7c). In contrast, although a slight electron density was seen in the matrix-like material surrounding aggregated bacteria around the cells cultured from non-CF patients, this material was more abundant and stained more heavily in cultures from $\mathrm{CF}$ patients (figs. $7 \mathrm{a}$ and $8 b)$.

\section{Immunocytochemical localisation of mucin}

Fluorescence assays showed that most of the epithelial respiratory cells were labelled by the MAb against rhesus monkey mucin (not shown). A fibrillar fluorescent material was seen surrounding the aggregated $P$. aeruginosa cells and, occasionally, linking bacteria to the ciliate cells.

Electronmicroscopy revealed that both $\mathrm{CC}$ and 

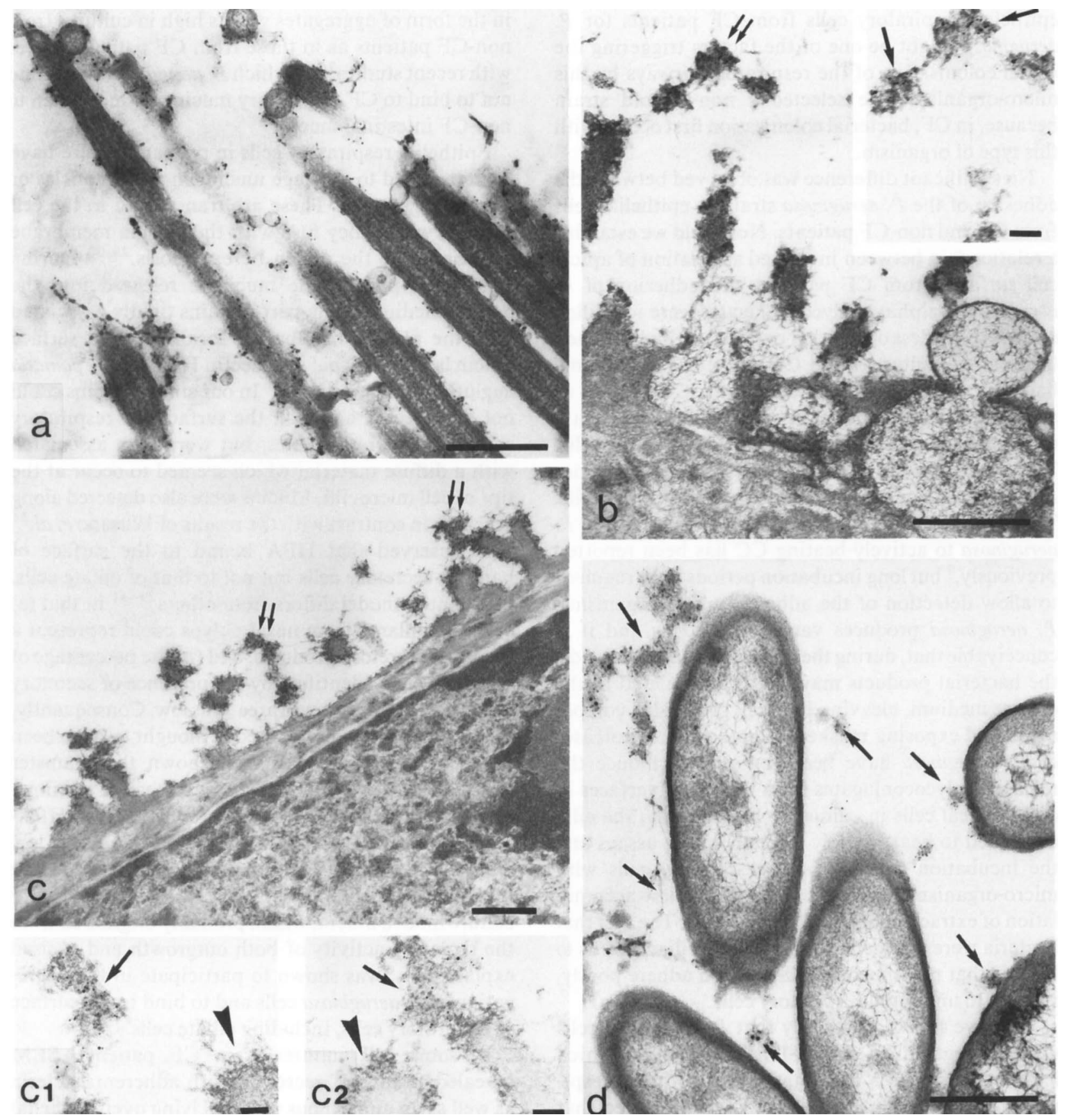

Fig. 8. Transmission electronmicrographs of respiratory ciliate (a) and non-ciliate cells (b, c) labelled with the anti-mucin MAb . Insets in b and $\mathbf{c}(1$ and 2 ) show higher magnifications of the microvilli (double arrows) from a secretory (b) and a non-secretory cell (c) labelled with the 5-nm colloidal gold granules. Labelling is not present along all the surface of the cells (arrowheads). In d, the labelling of the matrix-like material surrounding aggregated $P$. aeruginosa cells by the anti-mucin MAb is shown (arrows). Bars $=0.5 \mu \mathrm{m}$ generally, but $0.1 \mu \mathrm{m}$ for insets.

NCC were labelled by the anti-mucin MAb, but that labelling was restricted to the uppermost surfaces of cilia and microvilli (fig. 8a-c). Mucin was also identified in the matrix-like material which surrounded the bacteria (fig. 8d).

\section{Discussion}

In otherwise healthy persons, tracheobronchial infection by aerobic gram-negative bacilli is usually preceded by failure of the normal respiratory defence mechanisms. ${ }^{22}$ The available evidence suggests that the respiratory tracts of $\mathrm{CF}$ patients may not be damaged prior to infection. ${ }^{23}$ The factors predisposing CF patients to bacterial colonisation remain to be determined. However, the predominant mechanism allowing successful bacterial colonisation of the tracheobronchial tree is adhesion to epithelial cell receptors. Adhesion may prevent micro-organisms from being washed from the epithelial surface and may permit more effective delivery of bacterial products to the cell membrane. ${ }^{24}$ In this study, we evaluated whether specific adhesive properties of the 
epithelial respiratory cells from CF patients for $P$. aeruginosa might be one of the factors triggering the initial colonisation of the respiratory airways by this micro-organism. We selected a non-mucoid strain because, in CF, bacterial colonisation first occurs with this type of organism.

No significant difference was observed between the adhesion of the $P$. aeruginosa strain to epithelial cells from $C F$ and non-CF patients. Nor could we establish a relationship between increased sulphation of apical cell surfaces from CF patients and adhesion of $P$. aeruginosa: sulphated glycoconjugates were identified on cells regardless of whether or not these had attached bacteria. In cultures from $\mathrm{CF}$ and non-CF patients, bacteria were seen to associate with $\mathrm{CC}$ mainly as aggregates. This association appeared to occur via a matrix-like material surrounding the bacterial cells. This observation raises the question of whether or not $P$. aeruginosa can adhere to uninjured respiratory cells. The adhesion of clinical isolates of non-mucoid $P$. aeruginosa to actively-beating $\mathrm{CC}$ has been reported previously, ${ }^{7}$ but long incubation periods were required to allow detection of the adherent micro-organisms. $P$. aeruginosa produces various exotoxins and it is conceivable that, during these long incubation periods, the bacterial products may have accumulated in the culture medium, cleaving host cell glycocalyx components and exposing masked receptors. The proteases of $P$. aeruginosa have been reported to induce the release of glycoconjugates from the apical surfaces of dog tracheal cells in culture. ${ }^{25}$ In our study, the cilia continued to beat actively throughout the assays and the incubation period of the respiratory cells with micro-organisms was not so long as to allow accumulation of extracellular bacterial products. The fact that bacteria were not seen adhering to the cilia leads us to believe that non-mucoid $P$. aeruginosa adhere poorly, if at all, to uninjured respiratory cells.

We have shown previously that $P$. aeruginosa cells were aggregated by RPMI-HEPES medium which had previously been in contact with epithelial respiratory cells in culture for $1 \mathrm{~h}$ and we speculated that bacterial aggregation was induced by secretory products from the epithelial cells. ${ }^{21}$ Our hypothesis was supported by the observation that aggregation of $P$. aeruginosa cells was still observed when protein synthesis was blocked by pre-treatment of the microorganisms with gentamicin $10 \mathrm{mg} / \mathrm{L}$ for $1 \mathrm{~h}$. In the present study we observed that a MAb raised against respiratory mucins bound to the matrix-like material which surrounded the aggregated micro-organisms. These results suggest that the reactivity of the mucin may be responsible for bacterial aggregation. The affinity of $P$. aeruginosa for mucins from different origins, ${ }^{2,4,26}$ as well as the aggregation of the organism by salivary mucin, ${ }^{27,28}$ is well documented. Nevertheless, we cannot exclude the possibility that other secretory products from respiratory cells may have participated in the aggregation of $\boldsymbol{P}$. aeruginosa cells. Our observation that the proportion of bacteria present in the form of aggregates was as high in cultures from non-CF patients as in those from CF patients agrees with recent studies ${ }^{26}$ in which $P$. aeruginosa was found not to bind to CF respiratory mucin any more than to non-CF intestinal mucin.

Epithelial respiratory cells in primary culture have been reported to package mucins in small vesicles or secretory granules. These are transported to the cell surface, where they fuse with the plasma membrane and discharge the mucin by exocytosis. ${ }^{29,30}$ During exocytosis, part of the mucin is released into the culture medium while part remains tightly associated with the plasma membrane, forming a cell surface mucin layer, as revealed by lectin HPA (Helix pomatia agglutinin) reactivity. ${ }^{29,31}$ In our study, mucins could not be detected along all the surfaces of respiratory cells, even secretory ones, but were seen associated with a diffuse material which seemed to occur at the tips of cell microvilli. Mucins were also detected along the cilia, in contrast with the results of Wasano et al..$^{31}$ who observed that HPA bound to the surface of hamster secretory cells but not to that of ciliate cells. Our culture model differs from others ${ }^{29-31}$ in that (a) excised explants from nasal polyps could represent a source of secretory products, and (b) the percentage of secretory cells, identified by the presence of secretory granules in the outgrowth area, was low. Consequently, the amount of mucin secreted is thought to have been low. Previous work has been shown that hamster tracheal cells in culture for 3 days secrete minimal amounts of mucin and present only a few HPAreactive sites on their apical surfaces. ${ }^{29}$ Thus, the low secretory activity of our outgrowth cells may account for the poor mucin labelling of NCC surfaces. In our culture model, mucin, which probably originated from the secretory activity of both outgrowth and excised explant cells, was shown to participate in the aggregation of $P$. aeruginosa cells and to bind to the surface of respiratory cells, including ciliate cells

In some cell cultures from CF patients, SEM revealed strands of secretion with adherent bacteria as well as an amorphous material lying over epithelial cells. These strands could be the secretory products from respiratory cells. TEM showed that in cultures from $C F$ patients the bacteria were surrounded by a much more abundant mucin-containing matrix than that observed in cultures from non-CF patients. Accordingly, we suggest that respiratory cells from CF patients in culture have greater activity than cells from non-CF patients. This is in agreement with recent results from Merten et al. ${ }^{32}$ who showed that cultured tracheal glandular cells from CF patients had constitutive hypersecretory activity and were hyporesponsive to pharmacological agonists (forskolin and calcium ionophore). In our study, the hypersecretion of mucin by respiratory cells from CF patients did not account for a greater adhesion of $P$. aeruginosa. However, in vitro, the secretory products from epithelial cells were diluted in culture medium. In vivo, the paucity of water in CF respiratory secretions may alter 
their visco-elastic properties and result in the failure of mucociliary clearance. ${ }^{16}$ Therefore, it seems reasonable to speculate that, in vivo, both the marked mucin secretory activity of respiratory cells from CF patients and the abnormally high viscosity of the mucus may decisively favour the persistence of mucus-associated micro-organisms.

We thank Drs J. M. Klossek and C. Galabert for providing nasal polyps for this study, C. Fuchey and M. Menager for their excellent technical assistance and Dr D. Ploton for his helpful assistance.

This study was part of a collaborative research programme supported by INSERM-SYNTHELABO and AFLM, France and CAPES, Brazil

\section{References}

1. Puchelle E, Jacquot J, Beck G, Zahm JM, Galabert C. Rheological and transport properties of airway secretions in cystic fibrosis-relationships with the degree of infection and severity of the disease. Eur J Clin Invest 1985; 15 : 389 394.

2. Ramphal R, Pyle M. Evidence for mucins and sialic acid as receptors for Pseudomonas aeruginosa in the lower respiratory tract. Infect Immun 1983; 41 : 339-344.

3. Vishwanath $\mathrm{S}, \mathrm{Ramphal} \mathrm{R}$. Adherence of Pseudomonas aeruginosa to human tracheobronchial mucin. Infect Immun 1984; 45: 197-202.

4. Nelson JW, Tredgett MW, Sheehan JK, Thornton DJ, Notman $\mathrm{D}$, Govan JRW. Mucinophilic and chemotactic properties of Pseudomonas aeruginosa in relation to pulmonary colonization in cystic fibrosis. Infect Immun 1990; 58 : 14891495.

5. Baltimore RS, Christie CDC, Smith GJW. Immunohistopathological localization of Pseudomonas aeruginosa in lungs from patients with cystic fibrosis. Am Rev Respir Dis 1989; 140: 1650-1661.

6. Ramphal R, Houdret N, Koo L, Lamblin G, Roussel P. Differences in adhesion of Pseudomonas aeruginosa to mucin glycopeptides from sputa of patients with cystic fibrosis and chronic bronchitis. Infect Immun 1989; 57: 3066-3071.

7. Baker NR, Marcus H. Adherence of clinical isolates of Pseudomonas aeruginosa to hamster tracheal epithelium in vitro. Curr Microbiol 1982; 7: 35-40

8. Marcus H, Austria A, Baker NR. Adherence of Pseudomonas aeruginosa to tracheal epithelium. Infect Immun 1989; 57: 1050-1053.

9. Plotkowski MC, Beck G, Tournier JM, Bernardo-Filho M, Marques EA, Puchelle E. Adherence of Pseudomonas aeruginosa to respiratory epithelium and the effect of leucocyte elastase. J Med Microbiol 1989; 30: 285-293.

10. Niederman MS, Rafferty TD, Sasaki CT, Merrill WW, Matthay RA, Reynolds HY. Comparison of bacterial adherence to ciliated and squamous epithelial cells obtained from the human respiratory tract. Am Rev Respir Dis 1983; 127: 8590.

11. Franklin AL, Todd T, Gurman G, Black D, Mankinen-Irvin PM, Irvin RT. Adherence of Pseudomonas aeruginosa to cilia of human tracheal epithelial cells. Infect Immun 1987; 55: $1523-1525$.

12. Saiman L, Ishimoto $K$, Lory $S$, Prince $A$. The effect of piliation and exoproduct expression on the adherence of Pseudomonas aeruginosa to respiratory epithelial monolayers. $J$ Infect Dis 1990; 161 : 541-548.
13. Knowles M, Gatzy J, Boucher R. Increased bioelectrical potential difference across respiratory epithelia in cystic fibrosis. N Engl J Med 1981; 305: 1489-1495.

14. Frizzell RA, Rechkemmer G, Shoemaker RL. Altered regulation of airway epithelial cell chloride channels in cystic fibrosis. Science $1986 ; 233$ : 558-560.

15. Cheng P-W, Boat TF, Cranfill K, Yankaskas JR, Boucher RC Increased sulfation of glycoconjugates by cultured nasal epithelial cells from patients with cystic fibrosis. $J$ Clin Invest $1989 ; 84: 68-72$.

16. Boat TF, Cheng P-W. Epithelial cell dysfunction in cystic fibrosis: implications for airways disease. Acta Paediatr Scand 1989; 363 Suppl : 25-30.

17. Cheng SH, Gregory RJ, Marshall J et al. Defective intracellular transport and processing of CFTR is the molecular basis of most cystic fibrosis. Cell 1990; 63: 827-834.

18. Chevillard M, Hinnrasky J, Zahm J-M, Plotkowski M-C, Puchelle E. Proliferation, differentiation and ciliary beating of human respiratory ciliated cells in primary culture. Cell Tissue Res 1991 ; 264: 49-55.

19. Spicer SS, Hardin JH, Setsen ME. Ultrastructural visualization of sulphated complex carbohydrates in blood and epithelial cells with the high iron diamine procedure. Histochem $J$ $1978 ; 10: 435-452$.

20. St George JA, Cranz DL, Zicker SC, Etchison JR, Dungworth DL, Plopper CG. An immunohistochemical characterization of rhesus monkey respiratory secretions using monoclonal antibodies. Am Rev Respir Dis 1985; 132: 556-563.

21. Plotkowski MC, Chevillard M, Pierrot D et al. Differential adhesion of pseudomonas aeruginosa to human epithelial cells in primary culture. $J$ Clin Invest $1991 ; 87: 2018-2028$

22. Salata RA, Ellner JJ. Bacterial colonization of the tracheobronchial tree. Clin Chest Med 1988;9:623-633.

23. Sturgess JM. Mucus secretion and clearance in the pathogenesis of cystic fibrosis. Monogr Paed 1981; 14: 60-74.

24. Roberts DD. Interactions of respiratory pathogens with host cell surface and extracellular matrix components. $A m J$ Respir Cell Mol Biol 1990; 3: 181-186.

25. Varsano S, Basbaum CB, Forsberg LS, Borson DB, Caughey G, Nadel JA. Dog tracheal epithelial cells in culture synthesize sulfated macromolecular glycoconjugates and release them from the cell surface upon exposure to extracellular proteinases. Exp Lung Res 1987; 13: 157-184.

26. Sajjan U, Doig P, Reisman J, Irvin R, Forstner G, Forstner J. Binding of Pseudomonas aeruginosa to CF respiratory and normal intestinal mucins. Pediatr Pulmonol 1990; 5 Suppl: 241.

27. Komiyama K, Habbick BF, Tumber SK. Role of sialic acid in saliva-mediated aggregation of Pseudomonas aeruginosa to CF respiratory and normal intestinal mucins. Pediatr Pulmonol 1990; 5 Suppl: 241.

28. Komiyama K, Habbick BF, Tumber SK. Whole, submandibular, and parotid saliva-mediated aggregation of Pseudomonas aeruginosa in cystic fibrosis. Infect Immun 1989; 57 : 1229-1304.

29. Kim KC, Wasano K, Niles RM, Schuster JE, Stone PJ, Brody JS. Human neutrophil elastase releases cell surface mucins from primary cultures of hamster tracheal epithelial cells. Proc Natl Acad Sci USA 1987; 84: 9304-9308.

30. Kim KC, Nassiri J, Brody JS. Mechanisms of airway goblet cell mucin release: studies with cultured tracheal surface epithelial cells. Am J Respir Cell Mol Biol 1989; 1: 137143.

31. Wasano K, Kim KC, Niles RM, Brody J. Membrane differentiation markers of airway epithelial secretory cells. J Histochem Cytochem 1988; 36: 167-178.

32. Merten M, Roiron-Lagroux D, Puchelle E, Figarella C. Cultured cystic fibrosis tracheal glandular cells show constitutive hypersecretion and hyporesponsiveness to pharmacological agonists. Pediatr Pulmonol 1990; 5 Suppl: 232 